\title{
Numerical Modeling of turbidity currents with Ansys CFX and Telemac 3D
}

\author{
Magali Jodeau ${ }^{1, *}$, Sabine Chamoun ${ }^{2}$, Jiawei Feng ${ }^{3}$, Giovanni De Cesare ${ }^{2}$, and Anton J. \\ Schleiss ${ }^{2}$ \\ ${ }^{1}$ LNHE EDF, 6 quai Watier 78400 Chatou, France \\ ${ }^{2}$ LCH EPFL, Station 18, CH-1015 Lausanne, Switzerland \\ ${ }^{3}$ Tongji University, Shanghai, P.R. China
}

\begin{abstract}
Turbidity currents may be a relevant lever to manage the accumulation of fine sediments in reservoirs. In this paper, we propose to show how two different numerical codes simulate the propagation of turbidity currents. Telemac 3D and Ansys CFX 17.1 solver were chosen as they are commonly used by many research and engineering teams. The simulations are performed on two configurations. The first case aims at modeling the plunging of a turbidity current. The second model is validated based on an experimental work performed at EPFL. The latter consisted on testing turbidity current venting as a solution to manage reservoir sedimentation. A long and narrow flume was used to simulate the reservoir where a turbidity current was triggered. The advantages and limits of both approaches are discussed in order to supply guidelines for the modeling of turbidity currents in real reservoirs.
\end{abstract}

\section{Why modeling turbidity currents in reservoirs ?}

Sedimentation upstream of dams is a worldwide issue [1]. In order to define strategies for sediment management in reservoirs, the knowledge of turbidity currents is of utmost importance. Turbidity currents occur in reservoirs where the density of the incoming flow is significantly different from that of the still water of the lake. This difference of density is mainly due to the concentration of suspended sediments, but can also be affected by water temperatures. Depending on the water temperature in the lake, the turbidity current can flow at different elevations. The most common ones flow at the bottom of the reservoir. This phenomenon is also observed in deltas where sediment-laden rivers run into saline water.

Turbidity currents cause the accumulation of sediments in reservoirs and induce a vertical stratification affecting the water quality. When sedimentation has to be limited, turbidity currents may be a relevant lever to manage the accumulation of fine sediments in reservoirs.

Turbidity currents have specific dynamics. Compared with a homogeneous transport of sediments, sediment concentration and velocities are higher near the bottom. Physics of turbidity current is well known and has been described by many researchers since the 1950's [2-5]. Given the complexity of these turbulent currents, many tools have been used by researchers to improve the understanding and control of turbidity currents. These tools include

\footnotetext{
*e-mail: magali.jodeau@edf.fr
} 
theoretical analysis, experimental work and numerical modeling. The knowledge of transport characteristics may help in managing the sediments by e.g., designing silting basins, efficiently venting turbidity currents through bottom outlets [6], or building an obstacle to limit the propagation of the currents [7].

Theoretical analysis allow to determine the main characteristics of turbidity currents. Numerical models, either 1D vertical or 3D, allow to take into account complex bed topography, varying flows, sediments characteristics, etc. Many numerical studies on turbidity currents have been performed in the past using 3D CFD codes such as ANsys-CFX [8-10], FLow-3D [11, 12], Ssim 2 [13-17] , Delft3D [18], Ецсом [19].

In this paper we propose to show how two different numerical codes could simulate the propagation of turbidity currents. Telemac 3D and Ansys CFX 17.1 solvers were chosen as they are commonly used by many research and engineering teams. The simulations are performed on two configurations. The first case aims at modeling the plunging of a turbidity current. The second model is validated based on an experimental work performed at EPFL. The latter consisted on testing turbidity current venting as a solution to manage reservoir sedimentation. Ansys CFX 17.1 as well as the Telemac 3D models reproduced the experimental work. Based on these two examples, the advantages and limits of both approaches are discussed in order to supply guidelines for the modeling of turbidity currents in real reservoirs.

\section{Description of the numerical tools}

\subsection{Telemac 3D}

Telemac-Mascaret is a system of $1 \mathrm{D}, 2 \mathrm{D}$ and $3 \mathrm{D}$ open source codes with sediment and water quality modules (www.opentelemac.com). In the following paragraph, the equations used for sediment transport in Telemac 3D are given. The discretization in Telemac 3D is finite element method.

In this work the non-hydrostatic version is chosen and Telemac 3D solves the threedimensional mass and momentum conservation equations. Several turbulence models are implemented in Telemac 3D [20]. Suspended sediment transport is taken into account owing to an advection-dispersion equation. The boundary condition at the bed describes the exchanges of sediment with the bed, therefore it depends on the physical properties of the sediments. $\left(v_{t} \frac{\partial C}{\partial z}+w_{s} C\right)_{z=Z_{b}}=D-E$

The sediment deposition and erosion rates, respectively $D$ and $E$ depend on the bottom shear stress $\tau=\rho u_{*}^{2}$.

For sand, the deposition rate writes $D=w_{s} C_{b}$, where $w_{s}$ is the settling velocity and $C_{b}$ is the suspended concentration near the bottom (in Telemac 3D the concentration on the first free plane of the fluid is taken into account). The erosion rate writes $E=w_{s} C_{r e f}$. Theoretically, the reference concentration, $C_{\text {ref }}$ (or equilibrium concentration) is defined at a distance $z_{\text {ref }}$ from the bed which corresponds to the bed-load layer thickness. In Telemac-3D, several empirical formulae, such as Zyserman and Fredsoe [21] or van Rijn [22], could be used. $C_{b} \frac{\partial Z_{b}}{\partial t}=D-E$

Eventually, the fluid density $\rho$ is modified due to the sediment concentration

$$
\rho=\rho_{0}(1+\Delta \rho) \quad \text { with } \quad \Delta \rho=\frac{\rho_{s}-\rho_{0}}{\rho_{s} \rho_{0}} c
$$

where $\rho_{s}$ is the sediment density and $\rho_{0}$ the water density. 


\subsection{Ansys CFX 17.1}

Ansys CFX is a CFD commercial software. It employs a finite volume method to solve the Navier-Stokes equations [23]. However, thanks to its multiphase flow model, the code is well-adapted to model sediment-laden currents such as turbidity currents. Both the EulerianEulerian and Lagrangian methods are available in the software's code. For practical reasons, the Eulerian-Eulerian approach was chosen and sediment transport equations, represented by interfacial area density and interphase transfer between the water and sediment phases were solved using the Particle Model [23]. Regarding the turbulence model, a sensitivity analysis was done leading to the selection of the Shear Stress Transport (SST) model. For more information, all equations used in ANsys CFX code can be found in the program's user's guide [23].

An interesting aspect of Ansys CFX is that it allows the user to introduce equations to the code in the form of expressions, thus providing a better control and adaptation for each particular phenomenon simulated. In the case of the present work, the settling velocity as proposed by [24] was implemented in the code using the following equation:

$$
\frac{V_{s}}{V_{0}}=(1-C)^{m}
$$

where $V_{s}$ and $V_{0}$ are the particle's settling velocities in a suspension having a volumetric concentration $C$ and in clear water respectively. $m$ is a constant ranging between 2.25 and 7 according to [25]. Based on a sensitivity analysis, $m$ was set to 2.5. The definition used for $V_{0}$ can be found in [26]. Additionally, an expression was added for the drag coefficient following [27]. Finally, since Ansys CFX does not include expressions for the simulation of erosion and deposition of suspended sediments, an equation proposed by [22] was used and adapted. The latter provided a relationship between the mixture's dynamic viscosity $\mu_{m}$ and the sediment volumetric concentration $C$ as follows:

$$
\mu_{m}=\mu_{w}(1+\lambda)(1+0.5 \lambda)
$$

where $\mu_{w}$ is the dynamic viscosity of water and the parameter $\lambda$ was adapted for numerical conditions as such:

$$
\lambda=\left[\left(\frac{0.74}{0.73998 C+0.0001}\right)^{\frac{1}{3}}-1\right]^{-1}
$$

Note that the numerical model presented herein aims to complete an experimental work by extending the studied parameters (refer to section 4.1). Hence, all the different equations and parameters of the numerical model were chosen and validated in the aim of reducing the divergence between the numerical results and the experimental data.

\section{Modeling the plunging of a turbidity current with Telemac 3D}

Several empirical and theoretical studies between 1970 and 1990 have established a relationship between upstream flow characteristics and depth, $H_{p}$, at the plunging point [28]. For a straight flume with constant slope, it writes

$$
H_{p}=K\left(\frac{q_{0}^{2}}{\sqrt{g^{\prime}}}\right)^{1 / 3}
$$

Where $g^{\prime}=g \frac{\rho-\rho_{0}}{\rho_{0}}, g$ is the gravity. $K$ is a coefficient from 1.3 [29] to 1.6 [30]. Before using Telemac 3D for modeling turbidity currents in real reservoirs, it was checked if the code is 
able to reproduce the plunging of the current. A simplified model of a reservoir has been built.

The model is a straight flume, $1000 \mathrm{~m}$ long, $10 \mathrm{~m}$ wide, with a slope of $0.2 \%$. The upstream discharge is $2 \mathrm{~m}^{3} \mathrm{~s}^{-1}$, a downstream water depth of $1.5 \mathrm{~m}$ is prescribed. An upstream sediment concentration is prescribed, the downstream output of sediment is free. Initially the water is clear of sediment. Horizontal mesh size is $1 \mathrm{~m}, 30$ vertical layers with constant elevation are used. The $\mathrm{k}-\epsilon$ turbulence model has been chosen.

Several runs with upstream concentration from $10 \mathrm{gl}^{-1}$ to $150 \mathrm{gl}^{-1}$ have been performed. Figure 1 shows the concentration in the reservoir. The plunging of the turbid flow is well reproduced and the higher the concentration is, the nearer the plunging point is. Figure 2 plots the location of the modeled plunging points compared to Equation 5. Telemac 3D gives a very good modeling of the turbidity current plunging.

(a)

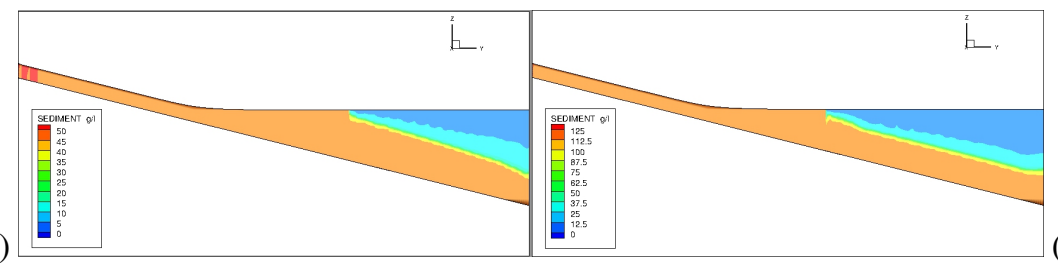

Figure 1. Concentration map in the simplified reservoir at $\mathrm{t}=2400 \mathrm{~s}$ for an usptream suspended concentration of $50 \mathrm{~g} / 1$ (a) and $125 \mathrm{~g} / \mathrm{l}(\mathrm{b})$.

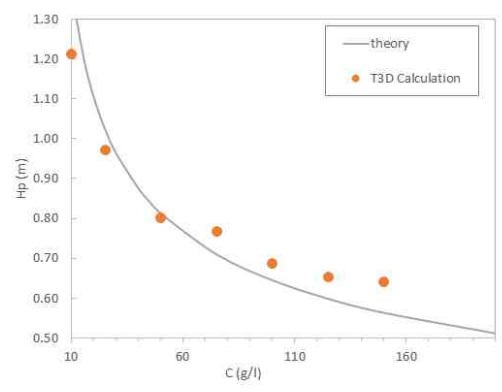

Figure 2. Depth of the plunging point depending on the upstream concentration: comparison between Equation 5 and Telemac 3D results

\section{Modeling turbidity current venting : comparison between experiment, Ansys CFX and Telemac 3D}

\subsection{Experiment description}

As previously mentioned, the numerical model built using Ansys CFX was validated on the basis of an experimental work. The experimental results were also used to check the robustness of the TELEMAC 3D model and for comparison purposes. 
The experimental set-up was built at the Laboratory of Hydraulic Constructions (LCH) at the Ecole Polytechnique de Lausanne (EPFL). The objective of the study was to investigate the operation of venting turbidity currents in the goal of reducing reservoir sedimentation [6]. This was achieved by selecting a number of parameters affecting the sediment release efficiency of venting and varying it. The scheme of the experimental model is shown in Figure 3. Summarily, it consists on a long $(8.55 \mathrm{~m})$ and narrow $(0.27 \mathrm{~m})$ flume linked to a mixing tank where the water-sediment mixture is prepared. The mixture is pumped into an initial reservoir called the head tank, from which it is led to the main flume once the inlet is opened. Turbidity currents are triggered due to the density difference between the concentrated flow and the clear water that is initially present in the main flume. The currents flow throughout the main flume and finally reach an outlet placed $6.7 \mathrm{~m}$ from the inlet. Venting starts at this moment by opening a valve with a preset outflow discharge. The vented flow is then transferred into a downstream basin. Several measurements are taken at the head tank, in the main flume and at the downstream basin throughout the tests. Notably, the inflow (turbidity current) and outflow (vented volume) discharges and concentrations, the sediment deposited mass in space and time, as well as velocity profiles are obtained. The wide range of measurements was a key aspect allowing the comparison between experimental and numerical data.

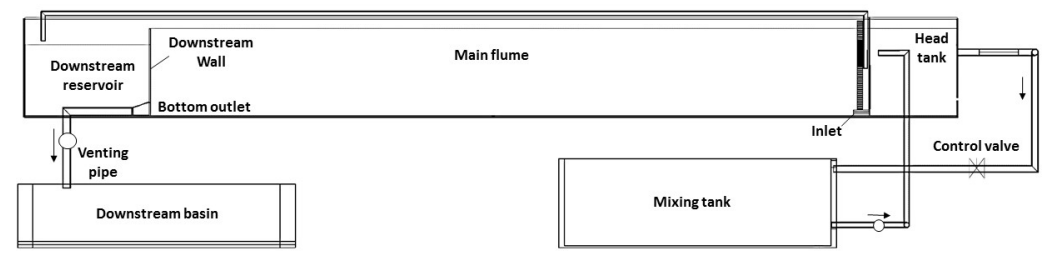

Figure 3. Scheme of the experimental apparatus.

\subsection{Ansys CFX results}

The geometry of the numerical model is three-dimensional, based on that of the experimental model. A large number of simulations led to a tetrahedral mesh except the near-bed region where an inflation was applied between the bottom and the main flume over a height of $32 \mathrm{~mm}$ (Figure 4). The inflation was used because the simulated turbidity currents were depositive. Therefore, the lower layer of the current needed a particularly fine mesh to allow for good modeling. The mesh consisted of some 524'393 elements.

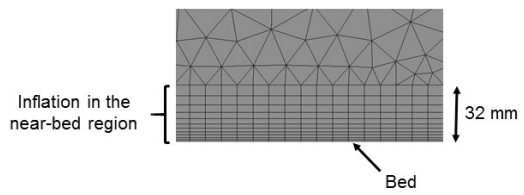

Figure 4. Bed inflation in the Ansys model meshing.

To assess the robustness of the numerical model, several parameters that were monitored during the experiments were chosen; the numerical and experimental data were then 
compared. Two parameters were selected in the frame of this paper: the outflow sediment concentration and the turbidity current's front velocity. The former is crucial for the determination of the release efficiency of venting. The latter is also important since the turbidity currents generated experimentally were highly depositive and therefore non-conservative. The turbidity currents decelerated during their advancement along the flume and therefore the dynamics was continuously changing.

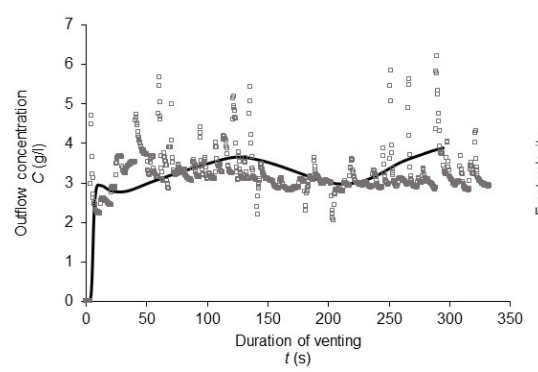

(a)

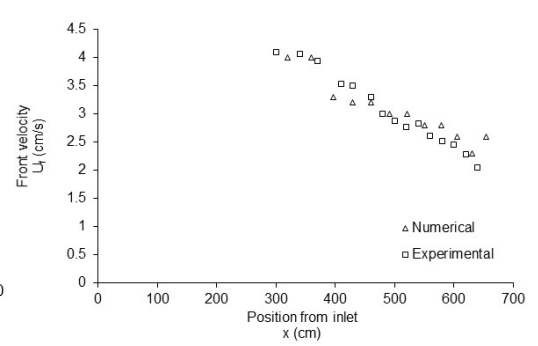

(b)

Figure 5. (a) Comparison between experimental and numerical outflow sediment concentrations as a function of venting duration. The solid line represents numerical data and squares represent experimental data (b) Comparison between experimental and numerical front velocities as a function of the distance from inlet.

The plot in Figure 5 (a) shows the outflow sediment concentration, $C$, as a function of time starting the beginning of venting. Both the experimental and numerical data show an initial increase in the concentration followed by a quasi-steady state corresponding to the stabilization of the conditions in the vicinity of the outlet. More explicitly, the outlet having a steady discharge/concentration in time, the turbidity currents are partly reflected by the downstream wall towards the upstream side of the flume and partly vented by the outlet operating with a constant outflow discharge in time. The overall deviation of numerical from experimental outflow concentration for all the tests done ranged around $14 \%$ to $20 \%$, which is very satisfying results given the complexity of the flow.

Moreover, front velocities, $\mathrm{U} f$, were plotted in space for both experimental and numerical tests (Figure $5 \mathrm{~b}$ ) showing quite similar negative slopes, meaning that the turbidity currents decelerate with a similar trend. The average numerical front velocities of the turbidity currents showed a deviation of only $2 \%$. Thus, the hydrodynamics of the currents was well represented numerically.

\subsection{Telemac 3D}

In this case, a 2D unstructured mesh with cell size $0.01 \mathrm{~m}$ and 60 planes irregularly spaced on the vertical are used leading to 36' 180 triangular elements and 2'170'800 3D elements . The time step of the calculation is $0.1 \mathrm{~s}$. The Manning-Strickler friction coefficient is $50 \mathrm{~m}^{1 / 3} \mathrm{~s}^{-1}$ and sediment have a median diameter of $132.8 \mu \mathrm{m}$ with a settling velocity of 1.5 $10^{-3} \mathrm{~ms}^{-1}$. Dynamic characteristics of the current were analyzed, this paragraph focus on the bed evolution calculated by TELEMAC 3D. The simulated deposition height are compared with the measurements in Figure 6. The evolution of the deposits is well captured by the numerical 
code even if it smoother and small discrepancy can be observed. In the experiment, the gate opening causes an initial acceleration and very high turbulence causing erosion, before the formation of the current. In the numerical model, this process was not simulated. This explains the difference between the two initial deposition values. Concerning the deposition near the dam site, unfortunately, the depositometer only reaches $6.2 \mathrm{~m}$ from the inlet while the wall representing the dam is positioned at $6.7 \mathrm{~m}$. For this reason, it was difficult to assess deposition close to the dam. However, it was visually possible to see that deposition still occurred in the upstream vicinity of the outlet after the arrival of the current. The main focus of this paper is not to go into the depth of the dynamic aspects of the currents but to present and compare two means for the simulation of the turbidity currents. RMSE-observations standard deviation ratio (RSR), was calculated. RSR standardizes RMSE using the observed standard deviation. It varies from 0.265 at the first time step to 0.509 which can be analyzed as very good or good. Therefore Telemac 3D reproduces the deposits of the turbidity current correctly.

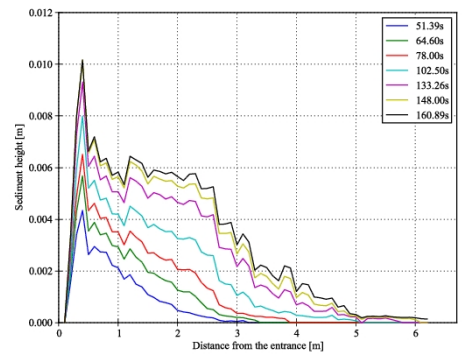

(a)

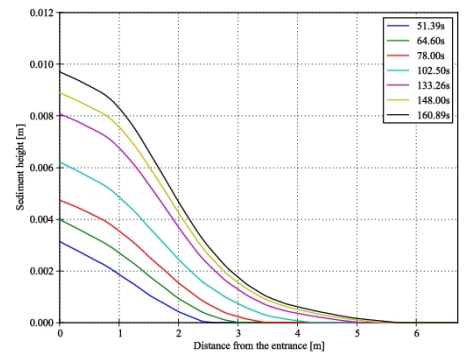

(b)

Figure 6. Sediment deposition height for several time values (a) experiment and (b) Telemac 3D simulation.

\section{Conclusion and Perspectives}

Modeling of turbidity currents is complex. It should take into account dynamic stratified flows with the difficulty of modeling sediment transport. The challenges of modeling vary depending on the context of the modeling, the aspects to study and the precision needed. Good modeling requires knowledge of theoretical, experimental and numerical literature supporting the user and improving the quality of the simulation.

In this paper, one theoretical and one experimental cases have been simulated using Telemac 3D and Ansys CFX showing good agreement with theory or experimental data. Modeling real reservoirs requires to account for other effects such as surface elevation variations, complex topography, several sediment grain sizes, etc. This paper underlines the capacity of both software to reproduce specific aspects of turbidity currents dynamics. Ansys is a user-friendly software with the possibility to adapt the code with user's expressions. Its main disadvantage is the absence of a deposition/erosion model for multiphase flows. TELEMAC 3D is an open source code which can be easily modified, the erosion/deposition model allows to simulate the bed evolution. The 3D mesh made of horizontal layers could make complex geometries such as dam structures difficult to integrate in the model. The next step of this work would be to compare both software on a real reservoir case. 


\section{Acknowledgments}

The study on venting turbidity currents was funded by Swisselectric Research and the Swiss Committee on Dams.

\section{References}

[1] A.J. Schleiss, M.J. Franca, C. Juez, G.D. Cesare, Journal of Hydraulic Research 54, 595 (2016)

[2] G. Parker, M. Garcia, Y. Fukushima, W. Yu, Journal of Hydraulic Research (1987)

[3] T. Ellison, J. Turner, Journal of Fluid Mechanics (1959)

[4] M. Garcia, Journal of hydraulic Engineering (1993)

[5] M. Altinakar, W. Graf, E. Hopfinger, Journal of Hydraulic Research (1996)

[6] S. Chamoun, G. De Cesare, A. Schleiss, international Journal of Sediment Research (2016)

[7] C. Oehy, A. Schleiss, Journal of Hydraulic Engineering (2007)

[8] G. De Cesare, A. Schleiss, F. Hermann, Journal of Hydraulic Engineering (2001)

[9] C. Oehy, G. De Cesare, A. Schleiss, Journal of Hydraulic Research 48, 81 (2010)

[10] S. Chamoun, influence of outlet discharge on the efficiency of turbidity current venting (2017)

[11] A. Sangdo, P. Julien, Journal of Hydraulic Engineering 140-5 (2014)

[12] A. Sang Do, Ph.D. thesis, Colorado State University (2011)

[13] N. Olsen, S. Haun, Free surface algorithms for 3D numerical modelling of reservoir flushing, in River Flow (2010)

[14] S. Haun, N. Olsen, Lakes and Reservoirs : Research and Management 17, 25 (2012)

[15] S. Haun, N. Olsen, International Journal of River Basin Management 10-4, 341 (2012)

[16] S. Haun, H. Kjaeras, S. Lovfall, N. Olsen, Journal of Hydrology 479, 180 (2013)

[17] G. Harb, S. Haun, J. Schneider, N. Olsen, International Journal of Sediment Research 29, 110 (2014)

[18] A.Y.A. Omer, Y.S.A. Ali, A. Roelvink, J. A. Dastgheib, P. Paron, A. Crosato, Earth Surface Dynamics (2014)

[19] S. Chung, M. Hipsey, J. Imberger, environmental modelling and software 24, 1467 (2009)

[20] J.M. Hervouet, Hydrodynamics of free surface flows, modelling with the finite element method (Wiley, 2007)

[21] J.A. Zyserman, J. Fredsoe, Journal of Hydraulic Engineering 120, 1021 (1994)

[22] L. Van Rijn, Ph.D. thesis, TU Delft (1987)

[23] ANSYS, Tech. rep. (2013)

[24] J. Richardson, W. Zaki, TRANS. INSTN CHEM. ENGRS, (1954)

[25] N. Chien, Z. Wan, Mechanics of sediment transport (1999)

[26] S. Zhiyao, W. Tingting, X. Fumin, L. Ruijie, Water Science Engineering (2008)

[27] N. Cheng, Journal of Hydraulic Engineering (1997)

[28] M. Garcia, Sedimentation engineering: processes, measurements, modeling, and practice (ASCE, 2008)

[29] B. Singh, Shah, La Houille Blanche (1971)

[30] G. Farell, H. Stefan, Journal of Hydraulic Research 26, 525 (1988) 